\title{
Evaluasi Program Pemberian Tablet Tambah Darah Pada Ibu Hamil di Puskesmas Gedongtengen
}

\author{
${ }^{1 *}$ Asep Rustiawan, ${ }^{1}$ Asty Pratiwi \\ ${ }^{1}$ Fakultas Kesehatan Masyarakat, Universitas Ahmad Dahlan \\ *Penulis korespondensi, email: asep.rustiawan@ikm.uad.ac.id
}

(Received: 30 February 2021/Accepted: 7 October 2021/Published: 31 January 2022)

\begin{abstract}
Abstrak
Pencegahan anemia pada ibu hamil dilakukan dengan memberikan minimal 90 tablet selama kehamilan. Cakupan TTD di wilayah kerja Puskesmas Gedongtengen masih berada di bawah target yang ditetapkan. Perlunya dilakukan monitoring dan evaluasi secara berkala pada pelaksanaan program suplementasi Fe untuk ibu hamil. Tujuan kegiatan pengabdian kepada masyarakat ini adalah mengevaluasi program pemberian TTD pada ibu hamil di Puskesmas Gedongtengen sesuai tahapan program. Metode yang digunakan dalam dalam kegiatan ini adalah dengan pendekatan studi kasus. Data primer diperoleh melalui wawancara mendalam dengan bidan, petugas gizi, farmasi dan ibu hamil secara purposive sampling. Data sekunder diperoleh dengan menyalin dokumen. Analisis data mengacu kepada Pedoman Program Pemberian Tablet Tambah Darah Untuk Ibu Hamil dan menggunakan pendekatan teori model Miles and Huberman. Hasil yang diperoleh yaitu pada tahap input, jumlah tenaga sesuai dengan kompetensinya, sumber dana berasal dari APBD, sarana yang digunakan tidak lengkap, ketersediaan TTD melalui jalur pemerintah. Pada tahap proses, perencanaan kebutuhan tersedia sesuai dengan jumlah sasaran, sosialisasi pemberian TTD dilakukan, penyimpanan TTD tidak lengkap, pendistribusian TTD melalui jalur pemerintah, cara pemberian TTD tidak sesuai kebutuhan, pencatatan dan pelaporan dilakukan, pemantauan dan evaluasi dilakukan. Pada tahap Output, cakupan program tidak mencapai target Standar Pelayanan Minimal (SPM) dan kepatuhan konsumsi TTD pada ibu hamil dikategorikan cukup patuh. Pada tahap outcome, prevalensi anemia berada di kategori berat.
\end{abstract}

Kata Kunci: Puskesmas Gedongtengen, Tablet Tambah Darah, Ibu hamil

\begin{abstract}
The prevention of anemia is done through an iron suplementation by providing at least 90 tablets during pregnancy. The iron supplement coverage obtained in Gedongtengen Public Health Center is still below the target. We need for monitoring and evaluation of implementation iron tablet program. The purpose is to evaluate the iron supplement program for pregnant women at the Gedongtengen Public Health Center. This research is descriptive qualitative study with a case study approach. Primary data was obtained through in-depth interviews with midwives, nutritionist, pharmacies and pregnant women by purposive sampling. Secondary data is obtained by copying documents. Data was analyzed using the guidelines for program of iron tablet for pregnant women and uses Miles and Huberman models theory. The result for the input stage, the number of personnel is in accordance with their competence, the source of funds comes from the $A P B D$, the facilities used are incomplete, the availability of iron tablets through government channels. At the process stage, planning needs are available according to the target number, dissemination of iron tablets is carried out, storage of iron tablets is incomplete, distribution of iron tablets through government channels, how to give iron tablets is not as needed, recording and reporting was carried out, monitoring and evaluation were carried out. At the Output stage, the program coverage did not reach the Minimum Service Standard and compliance with iron
\end{abstract}


supplement consumption for pregnant women was categorized as quite obedient. At the outcome stage, the prevalence of anemia was in the severe category.

Keywords : Gedongtengen Public Health Center, Iron Tablets Suplement, Pregnant women

\section{Pendahuluan}

Status gizi ibu sejak sebelum hamil hingga hamil akan mempengaruhi pertumbuhan janin dalam kandungan sehingga berpengaruh pada kualitas bayi yang dilahirkan. Ibu yang memiliki gizi yang normal akan meningkatkan peluang untuk melahirkan bayi yang sehat dan memiliki berat badan lahir yang normal (Dewantoro dan Muniroh, 2017). Resiko yang ditimbulkan dari ibu hamil anemia adalah bayi yang dilahirkan juga akan mengalami anemia defisiensi Fe yang jika dibiarkan akan berakibat pada pertumbuhan dan perkembangan menjadi terhambat (Kemenkes RI, 2015a).

Berdasarkan hasil Riskesdas (2018), prevalensi ibu hamil yang menderita anemia di Indonesia mengalami peningkatan di tahun 2013 sebesar 37,1\% dan tahun 2018 menjadi 48,9\%. Sebagian besar prevalensi anemia diderita oleh ibu hamil dengan kelompok usia 15-24 tahun yaitu sebesar $84,6 \%$. Angka prevalensi anemia di Indonesia lebih tinggi daripada angka rata-rata prevalensi anemia di Negara maju. Oleh sebab itu, anemia pada ibu hamil masih menjadi masalah kesehatan yang perlu diperhatikan karena memiliki prevalensi lebih dari 20\% (Kemenkes RI 2019).

Ibu hamil membutuhkan vitamin dan mineral selama kehamilannya. Setiap ibu hamil memerlukan vitamin untuk bayi dan dirinya sendiri. Kebutuhan zat besi akan meningkat pada trimester kedua dan biasanya jumlah zat besi tidak tersedia pada sebagian besar ibu hamil dan untuk mengoptimalkan volume eritrosit maka perlu pemberian suplemen zat besi. Oleh sebab itu, ibu hamil memerlukan Tablet Tambah Darah (TTD) untuk mencegah dan menanggulangi anemia. Ibu hamil disarankan mengonsumsi TTD minimal 90 tablet selama kehamilan (Kemenkes RI, 2018).

Meskipun program suplementasi TTD telah dilakukan, angka prevalensi anemia masih tetap tinggi (Rahmiati, 2019). Puskesmas Gedongtengen memiliki prevalensi anemia pada ibu hamil dengan kategori berat selama tiga tahun berturut-turut, dimana puncaknya berada di tahun 2017 yaitu sebesar 66\%. Jumlah prevalensi anemia pada ibu hamil berhubungan dengan kepatuhan konsumsi TTD pada ibu hamil (Lacerte et al., 2011). Konsumsi TTD berhubungan dengan pelaksanaan program TTD yang berpengaruh terhadap kepatuhan konsumsi Fe dan cakupan pemberian Fe serta dampaknya berupa kejadian anemia (Haddad et al., 2016).

Indikator keberhasilan program anemia gizi besi diantaranya cakupan distribusi, kepatuhan konsumsi TTD dan prevalensi anemia pada ibu hamil. Guna memantau keberhasilan program maka perlunya dilakukan evaluasi baik melalui input, process, output maupun outcome. Evaluasi dapat dilakukan baik pada sasaran maupun pada program (Kemenkes RI, 2015a). Evaluasi merupakan kegiatan penilaian terhadap keberhasilan atau kegagalan suatu program intervensi yang dilakukan secara berkala (Irianto, 2014). Evaluasi input ditujukan kepada penggunaan sumber daya dalam program, meliputi tenaga pelaksana, sumber dana, maupun sarana dan prasarana. Tahap process yaitu tahap administrasi meliputi perencanaan, pengorganisasian, pelaksanaan dan penilaian. Tahap output digunakan untuk menilai suatu program tersebut berhasil dan tujuan dari suatu program tercapai atau tidak. Tahap outcome digunakan untuk mengetahui apakah program ini membawa dampak bagi peningkatan kesehatan masyarakat (Notoatmodjo, 2011)

Tujuan umum kegiatan pengabdian ini adalah mengevaluasi program pemberian Tablet Tambah Darah Kepada Ibu Hamil di Puskesmas Gedongtengen. 


\section{Metode}

Sampel dalam kegiatan ini dinamakan narasumber atau informan. Data primer pada tahap input yaitu tenaga, sumber dana, sarana dan ketersediaan TTD; tahap proses yaitu perencanaan kebutuhan, sosialisasi pemberian, penyimpanan TTD, penditribusian, cara pemberian, pencatatan dan pelaporan serta pemantauan dan evaluasi; tahap output yaitu cakupan program dan kepatuhan konsumsi TTD; tahap outcome yaitu prevalensi anemia. Data tersebut diperoleh melalui wawancara langsung dengan informan secara daring (online) melalui WhatsApp. Observasi dilakukan secara langsung oleh peneliti yang terdiri dari surat tugas bagi petugas kesehatan dan rekam medis ibu hamil serta dokumen pencatatan dan pelaporan yang dimiliki oleh Puskesmas. Observasi dilakukan pada saat jadwal pelayanan ANC agar lebih mudah dalam mengamati dengan tetap mematuhi protokol kesehatan selama pandemi Covid-19, yaitu dengan menggunakan masker dan jaga jarak. Data sekunder diperoleh dengan mencatat atau menyalin dokumen tentang cakupan $\mathrm{Fe}$ dan jumlah prevalensi ibu hamil anemia di Puskesmas Gedongtengen.

Analisis data mengacu kepada Pedoman Program Pemberian Tambah Darah Untuk Ibu Hamil dan menggunakan pendekatan teori dari Milles and Hubberman (Miles et al., 2014). Proses kegiatan dalam analisis data memiliki beberapa tahap, yaitu: pengumpulan data, reduksi data, penyajian data, dan penarikan kesimpulan atau verifikasi data. Tahap dalam analisis data pada kegiatan ini meliputi : 1) mencatat semua hasil temuan baik melaui wawancara, observasi maupun dokumentasi, 2) mencermati kembali catatan dari hasil temuan kemudian memisahkan data yang peneliti anggap penting dan tidak penting dan mengulanginya kembali agar meminimalisir kesalahan, 3) mendeskripsikan data yang sudah dikelompokan sesuai dengan masalah, 4) membuat kesimpulan hasil analisis setelah di verifikasi dengan bukti yang ditemukan menjadi suatu laporan hasil pengabdian.

\section{Hasil dan Pembahasan}

\section{1. Indikator Input}

Hasil evaluasi program pemberian TTD pada ibu hamil di Puskesmas Gedongtengen. Berdasarkan hasil observasi dan wawancara, telah memperoleh hasil tahapan input.

Tabel 1. Hasil Indikator Input

\begin{tabular}{|c|c|c|}
\hline Variabel & Kategori & Hasil \\
\hline Tenaga & Sesuai & $\begin{array}{l}\text { Petugas kesehatan bertugas sesuai dengan } \\
\text { kompetensinya }\end{array}$ \\
\hline Dana & APBD & $\begin{array}{l}\text { Sumber dana yang digunakan Puskesmas } \\
\text { menggunakan APBD. }\end{array}$ \\
\hline $\begin{array}{l}\text { Sarana dan } \\
\text { prasarana }\end{array}$ & Tidak Lengkap & $\begin{array}{l}\text { Buku KIA, Kohort, dan register ibu hamil dan formulir } \\
\text { pencatatan dan pelaporannya ada, tetapi juknis tidak } \\
\text { ada. }\end{array}$ \\
\hline $\begin{array}{l}\text { Ketersediaan } \\
\text { TTD }\end{array}$ & Jalur Pemerintah & $\begin{array}{l}\text { Pengadaan TTD dilakukan oleh Dinas Kesehatan } \\
\text { melalui dana APBD. }\end{array}$ \\
\hline
\end{tabular}

Sumber : Data Primer, 2021

Berdasarkan Tabel 1, hasil indikator input dari segi tenaga, dana, dan ketersediaan TTD sesuai dengan pedoman pemberian TTD pada ibu hamil. Sedangkan dari segi sarana dan prasarana tidak sesuai dengan pedoman pemberian TTD pada ibu hamil. Berdasarkan hasil wawancara mengenai indikator input diperkuat oleh penjelasan informan A2 dan informan A3. 
"kalau kita memiliki buku KIA, kohort ibu hamil, register ibu hamil, buku pedoman penatalaksanaan pemberian TTD, untuk juknisnya tidak ada, formulir pencatatan pelaporannya tidak ada, saya hanya merekap di buku gizi sendiri kemudian saya cocokan dengan data KIA agar hasilnya serasi" (A2).

"Farmasi punya formulir penerimaan TTD dan distribusi TTD yaitu LPLPO (Laporan Pemakaian dan Lembar Permintaan Obat) jadi untuk memantau stok obatnya, kalo formulir inspeksi gudang kita belum ada, adanya cuma SOP (Standar Operasional Prosedur) saja" (A3).

Berdasarkan indikator input dari segi tenaga, Puskesmas Gedongtengen memiliki delapan tenaga kesehatan yang terdiri dari petugas Gizi, Bidan, dan farmasi. Kepala Puskesmas bertanggung jawab dalam membawahi tenaga kesehatan yang terlibat dalam program suplementasi Fe yang mana secara keseluruhan berada di bawah tanggungjawab Seksi Gizi Dinas Kesehatan (Purwati et al., 2016). Sumber dana yang digunakan oleh Pemerintah Kota Yogyakarta menggunakan APBD Kota Yogyakarta. Dana yang digunakan dalam pelaksanaan program pemberian TTD menggunakan sumber dana APBD/APBN atau sumber dana lainnya (MCAI, 2015). Sumber dana yang digunakan dalam menjalankan program pemberian Fe berasal dari sumber dana APBN/ABPD atau dari sumber dana yang lainnya (Kemenkes RI, 2015b). Puskesmas Gedongtengen belum memiliki petunjuk teknis mengenai pemberian TTD pada ibu hamil sehingga memiliki dampak terhadap proses pelayanan distribusi suplementasi TTD seperti dosis pemberian TTD pada ibu hamil anemia. Pemerintah diharapkan dapat menentukan kebijakan berupa adanya petunjuk teknis untuk mempermudah petugas pelaksana dalam melakukan kegiatan pemberian TTD pada ibu hamil.

Hal tersebut sejalan dengan penelitian yang dilakukan oleh Tuju yang menyatakan bahwa petunjuk teknis dan petunjuk pelaksanaan dalam suatu program dapat membantu program agar terlaksana dengan teratur oleh tenaga pelaksana di tingkat Puskesmas (Tuju et al., 2013). Petunjuk teknis dan petunjuk pelaksanaan dapat digunakan sebagai pedoman dalam melaksanakan suatu program agar dapat berjalan dengan selaras dan menghindari dari kesalahan dalam menjalankan suatu kebijakan dan dapat menjadi pedoman bagi pembuat kebijakan dalam melakukan implementasi kebijakan (Winarno, 2012). Suatu kebijakan program membutuhkan sarana yang dapat digunakan untuk menjalankan suatu program berupa kebijakan, peraturan, petunjuk teknis, petunjuk pelaksanaan serta SOP untuk mengubah input menjadi output (Purwati et al., 2016).

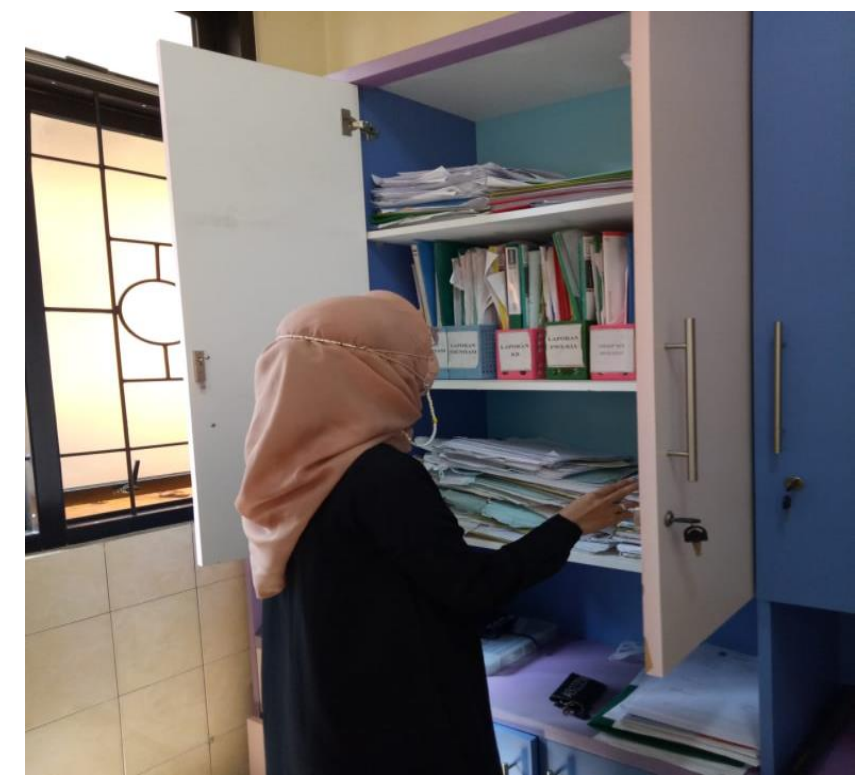

Gambar 1. Observasi Kelengkapan Sarana dan Prasarana 
3. 2. Indikator Proses

Tabel 2. Hasil Indikator Proses

\begin{tabular}{lll}
\hline \multicolumn{1}{c}{ Variabel } & \multicolumn{1}{c}{ Kategori } & \multicolumn{1}{c}{ Hasil } \\
\hline $\begin{array}{l}\text { Perencanaan } \\
\text { Kebutuhan }\end{array}$ & Tersedia & $\begin{array}{l}\text { Kesediaan TTD di Puskesmas Gedongtengen mencukupi } \\
\text { jumlah sasaran ibu hamil tahun 2020. }\end{array}$ \\
\hline Sosialisasi Pemberian & Dilakukan & $\begin{array}{l}\text { Petugas Kesehatan melakukan penyuluhan mengenai } \\
\text { manfaat, efek samping, cara minum TTD. }\end{array}$ \\
\hline Penyimpanan TTD & Tidak Lengkap & $\begin{array}{l}\text { Tata letak dan cara penyimpanan berdasarkan FIFO atau } \\
\text { FEFO, tetapi tidak memiliki formulir inspeksi gudang } \\
\text { dan lingkungan di tingkat puskesmas untuk dilaporkan } \\
\text { ke Dinas }\end{array}$ \\
& & $\begin{array}{l}\text { Proses pengiriman TTD berasal dari Dinas Kesehatan } \\
\text { Kota Yogyakarta. Sehingga melalui jalur pemerintah. }\end{array}$ \\
& Dalur & Distribusi dilakukan setiap bulan. \\
\hline Pendistribusian & Pemerintah & $\begin{array}{l}\text { Ibu hamil anemia belum diberikan TTD sesuai } \\
\text { kebutuhannya. Evaluasi status anemia tidak dilakukan } \\
\text { sesuai pedoman. }\end{array}$ \\
\hline $\begin{array}{ll}\text { Cara Pemberian } \\
\text { Tidak Sesuai }\end{array}$ & & $\begin{array}{l}\text { Bidan, petugas gizi, dan farmasi memiliki kelengkapan } \\
\text { dokumen pencatatan dan pelaporan tersendiri. }\end{array}$ \\
\hline $\begin{array}{l}\text { Pencatatan dan } \\
\text { pelaporan }\end{array}$ & Dilakukan & $\begin{array}{l}\text { Dinas Kesehatan rutin melakukan pemantauan melalui } \\
\text { laporan yang dilakukan oleh Puskesmas. }\end{array}$ \\
\hline $\begin{array}{l}\text { Pemantauan dan } \\
\text { evaluasi }\end{array}$ & Dilakukan &
\end{tabular}

Sumber : Data Primer, 2021

Berdasarkan Tabel 2, hasil indikator proses dari segi penyimpanan TTD dan cara pemberian tidak sesuai dengan pedoman pemberian TTD pada ibu hamil. Berdasarkan hasil wawancara mengenai indikator proses diperkuat oleh informan A1 dan informan A3.

"Sistem penyimpanan sama dengan tablet yang lain, jadi setelah tablet diterima lalu disimpan sesuai bentuk sediaan, menggunakan manajemen FIFO/FEFO jadi obat yang masuk duluan/kaduluwarsa duluan akan dikeluarkan terlebih dahulu, kalau formulir inspeksi gudang dan lingkungan di Tingkat Puskesmas tidak ada, adanya SOP penyimpanan saja, sama pemantauan stok saja, kalau laporan ke Dinas hanya LPLPO jadi lebih ke stoknya" (A3).

"Pemberian TTD sesuai usia kehamilan, kalau kunjungan sebelumnya obatnya masih jadi kita tidak memberikan sesuai usia kehamilan, tetapi sampai cukup untuk kunjungan berikutnya, kalau ibu hamil anemia kita berikan TTD 2xl hari selama satu bulan. Sedangkan pemeriksaan Hb pada ibu hamil trimester I dan II dilakukan setiap 3 bulan sesuai program ANC terpadu" (A1)

Berdasarkan indikator proses, Puskesmas membuat permintaan suplementasi Fe setiap bulan ke Dinas Kesehatan dengan menggunakan Laporan Pemakaian dan Lembar Permintaan Obat (Form LPLPO) (Septiani, 2017). Sosialisasi yang diberikan diantaranya manfaat, efek samping, cara konsumsi TTD. Sosialisasi diberikan agar meningkatkan kepatuhan ibu hamil dalam konsumsi TTD. Ibu hamil perlu diberikan sosialisasi agar menjadi tahu, dan mau sehingga dapat menjadi patuh untuk mengonsumsi TTD sesuai dengan anjuran bidan. Petugas kesehatan memiliki tugas sebagai komunikator yaitu memberikan informasi tentang anemia kepada ibu hamil. Guna meminimalisir kurangnya pengetahuan dan sikap ibu hamil terhadap kesehatan dirinya diperlukan pemberian informasi. Komunikasi dari petugas kesehatan sangat diperlukan. Petugas kesehatan memiliki tugas sebagai motivator dan mampu mendengarkan permasalahan yang disampaikan oleh ibu hamil serta memberikan dukungan moril kepada ibu hamil (Handayani, 2013).

Cara penyimpanan berdasarkan FIFO (First In First Out) dan atau FEFO (First Expired First Out) yaitu obat yang lebih dahulu diterima dan/atau memiliki tanggal kadaluwarsa lebih 
dahulu akan dikeluarkan dahulu. Memiliki kondisi gudang yang memadai seperti kelembaban (< $75 \%)$, kebersihan, suhu $\left(<30^{\circ} \mathrm{C}\right)$ dan kemampuan untuk mencegah terjadinya kontaminasi merupakan salah satu faktor penting untuk menjaga kualitas produk. akses ketika membersihkan dan juga ventilasi perlu diperhatikan dalam mengatur tata letak dan kondisi gudang (MCAI, 2015). Distribusi TTD di Puskesmas Gedongtengen dilakukan secara bertingkat yaitu dari Provinsi, Kabupaten/Kota, Puskesmas dan sampai ke ibu hamil.

Cara pemberian TTD pada ibu hamil dengan dosis pencegahan anemia sebanyak 1 TTD setiap hari atau minimal 90 tablet selama kehamilan. Tetapi, untuk dosis pengobatan pada ibu hamil anemia masih belum sesuai dengan kebutuhan. Hal itu dikarenakan dosis pengobatan sebanyak 2 tablet setiap hari hanya diberikan selama satu bulan dan pemeriksaan $\mathrm{Hb}$ pada ibu hamil trimester I dan II dilakukan setiap tiga bulan.

Hal tersebut tidak sesuai dengan pedoman pemberian TTD Kemenkes RI yang menyatakan bahwa dosis suplementasi Fe yang diberikan ibu hamil anemia sebanyak dua tablet yang harus diminum setiap hari sampai dengan kadar $\mathrm{Hb}$ mencapai normal. Ibu hamil anemia memeriksakan kadar $\mathrm{Hb}$ dengan ketentuan apabila ibu hamil terdeteksi anemia pada trimester I maka pemeriksaan $\mathrm{Hb}$ dilakukan setiap bulan sampai dengan $\mathrm{Hb}$ mencapai normal. Jika ibu hamil terdeteksi anemia pada trimester II maka pemeriksaan $\mathrm{Hb}$ dilakukan setiap dua minggu sampai dengan $\mathrm{Hb}$ mencapai normal. Jika pada pemeriksaan $\mathrm{Hb}$ berikutnya tidak mengalami perubahan maka sebaiknya langsung dirujuk ke fasilitas kesehatan yang lebih tinggi. Hal tersebut dikarenakan apabila anemia disebabkan oleh defisiensi besi, kadar $\mathrm{Hb}$ akan meningkat dalam satu bulan setelah mengonsumsi TTD secara teratur. Sedangkan apabila kadar Hb tidak berubah setelah mengonsumsi TTD secara teratur, maka kemungkinan bukan disebabkan oleh defisiensi besi (Kemenkes RI, 2015a). Hal tersebut sesuai dengan penelitian yang dilakukan oleh Rooselyn (2016) yang menyatakan bahwa mengonsumsi TTD secara teratur dapat menghilangkan tandatanda kekurangan darah, apabila tidak terjadi peningkatan $\mathrm{Hb}$ maka ibu hamil tersebut bukan menderita anemia gizi besi melainkan anemia jenis yang lain.

Selain itu, apabila tidak terjadi kenaikan $\mathrm{Hb}$ dalam waktu satu bulan konsumsi TTD secara teratur, maka patut dicurigai : 1) TTD tidak dikonsumsi, 2) TTD dikonsumsi tetapi tidak sesuai dengan anjuran, 3) Terdapat infeksi parasit/kronis atau cacingan, 4) Ibu hamil banyak mengonsumsi bahan makanan yang dapat menghambat penyerapan Fe misalnya fitat dan tanin, 5) Mempercayai dan mengikuti mitos yang berlainan dengan ilmu pengetahuan (Kemenkes RI, 2015a). Status anemia pada ibu hamil perlu dilakukan evaluasi secara periodik (Kemenkes RI, 2015b). Oleh sebab itu, pemeriksaan kadar Hb perlu dilakukan secara berkala sesuai dengan kebutuhan ibu hamil untuk mengetahui penyebab terjadinya anemia pada ibu hamil.

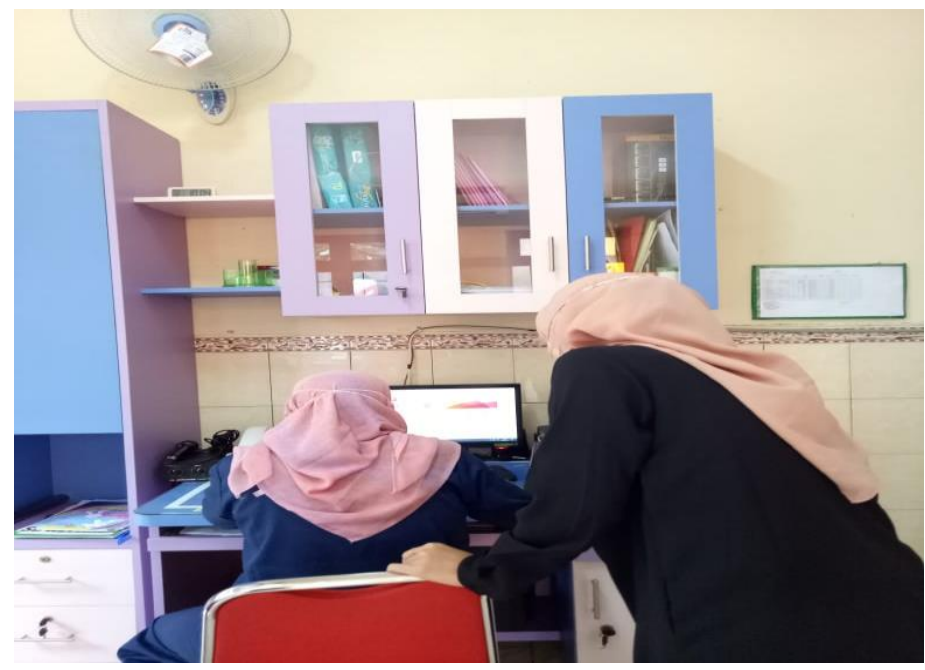

Gambar 2. Observasi Pencatatan dan Pelaporan 
Proses pencatatan dan pelaporan dilakukan secara berjenjang mulai dari posyandu, Puskesmas sampai pusat. Pencatatan tingkat puskesmas terdiri dari buku KIA, kohort ANC, dan laporan bulanan hasil rekapitulasi pemberian TTD ibu hamil. Bidan memiliki tugas mendistribusikan TTD kepada semua ibu hamil yang melakukan pemeriksaan kehamilan di poli KIA dan mencatat di buku KIA selanjutnya setelah dilakukan tindakan, bidan mencatat di kohort ANC. Merekapitulasi laporan bulanan pemberian TTD pada register ANC. Kemudian laporan hasil rekapan pemberian TTD pada ibu hamil dikirim ke Dinas Kesehatan Kabupaten dan Kota paling lambat pada 10 bulan berikutnya (Kemenkes RI, 2015b).

Pemantauan dilakukan melalui dua cara, yaitu analisis data laporan rutin dan kunjungan lapangan. Analisis data rutin diharapkan dapat digunakan untuk identifikasi masalah pada proses pelaksanaan program dalam hal apa dan dimana kegiatan dilakukan sehingga saran dan masukan yang diberikan sesuai dengan permasalahan serta rencana tindak lanjut yang perlu dilakukan. Kunjungan ke lapangan dilakukan untuk mengumpulkan informasi secara langsung sehingga dapat menentukan langkah tindak lanjut atau saat peningkatan kapasitas lebih lanjut (MCAI, 2015).

\section{3. Indikator Output}

Hasil indikator output dari segi cakupan Fe ditahun 2020 di Puskesmas Gedongtengen berdasarkan hasil tela'ah dokumen diperoleh hasil cakupan $\mathrm{Fe} 1$ dan $\mathrm{Fe} 3$ sebesar 97,80\% dan 61,54\%. Hal tersebut menunjukkan bahwa cakupan Fe1 dan Fe3 di Puskesmas Gedongtengen belum mencapai target Indonesia sehat tahun 2019 yaitu sebesar 98\%. Sedangkan dari segi kepatuhan ibu hamil mengkonsumsi TTD di kategorikan cukup patuh karena memiliki tingkat kepatuhan $\geq 65 \%$. Hasil wawancara mengenai tingkat kepatuhan ibu hamil dalam mengkonsumsi TTD yang dilakukan pada ibu hamil di Puskesmas Gedongtengen diperkuat oleh penjelasan informasi A4 dan informan A5.

"Saya terkadang lupa 1-2 kali minum tablet tambah darah karena belum sarapan terus niatnya diminum di tempat kerja malah kelupaan. Ya sebelumnya sudah dikasih tau kalau disuruh minum malam, tapi saya pikir sama aja diminum pagi atau malam, jadi saya barengkan saja minumnya pagi semua sama tablet satunya (kalsium) itu” (A4).

"Saya tidak rutin minum tablet tambah darah bu, karena mual setelah minum tablet tambah darah itu, apalagi saya minum di tempat kerja. Misalnya dari 30 tablet yang dikasih bu bidan, pasti selalu sisa 5-10 tablet setiap bulannya karena mual dan lupa. Petugas kesehatan sudah memberitahu kalau diminum malam, tetapi saya kira tidak ada hubungannya mau di minum pagi atau malam jadi saya minum pagi sekalian" (A5).

Penyebab belum tercapainya target Fe1 dan Fe3 di Puskesmas Gedongtengen adalah mobilitas ibu hamil sangat tinggi dan terjadinya under reporting karena pencatatan yang dilakukan ketika ibu hamil memeriksakan kehamilannya diluar Puskesmas tidak optimal serta ibu hamil yang mulai memeriksakan kehamilannya pada usia kehamilan trimester 2 dan 3. Ibu hamil yang tidak teratur dalam memeriksakan kehamilannya disebabkan oleh ibu hamil yang mulai memeriksakan kehamilannya pada trimester II dan III (Nurmasari and Sumarmi 2019). Anemia pada ibu hamil dipengaruhi oleh beberapa faktor yaitu tingkat kepatuhan ibu hamil dalam mengonsumsi suplementasi Fe, frekuensi kunjungan ANC, dan pola makan ibu hamil tersebut (Pavord et al., 2012). Hal tersebut sesuai dengan pernyataan Dinkes DIY (2020) yang menyatakan bahwa penyebab rendahnya cakupan Fe di DIY karena rendahnya cakupan K4 yang disebabkan oleh mobilitas ibu hamil yang tinggi, tingginya akses ibu hamil K1 di trimester II, pencatatan dan 
pendataan ibu hamil yang mendapatkan TTD diluar Puskesmas belum optimal, serta belum optimalnya pemantauan yang dilakukan oleh kader pendamping ibu hamil.

Berdasarkan hasil wawancara yang telah dilakukan, kedua ibu hamil tersebut memiliki tingkat kepatuhan yaitu cukup patuh. Terdapat beberapa faktor ketidakpatuhan informan dalam konsumsi TTD yaitu lupa dan perasaan mual ketika meminum TTD. Selain itu, ibu hamil juga mengatakan tidak mengetahui aturan minum TTD yang benar serta efek samping yang ditimbulkan dari TTD, sehingga rendahnya pengetahuan ibu hamil mengenai TTD berdampak pada tingginya jumlah prevalensi anemia pada ibu hamil. Ibu hamil tersebut mengatakan bahwa tidak mengetahui jika TTD tidak dapat dikonsumsi bersama dengan Kalsium karena dapat mengganggu penyerapan Fe. Tingkat kepatuhan ibu hamil dalam mengonsumsi TTD dapat disebabkan oleh beberapa faktor, antara lain munculnya rasa bosan pada ibu hamil karena harus mengonsusi tablet $\mathrm{Fe}$ setiap hari selama kehamilannya, beberapa ibu hamil lupa mengonsumsi tablet Fe karena keluarga tidak ada yang mengawasi atau mengingatkan. Selain itu, munculnya rasa mual karena aroma yang tidak sedap pada tablet Fe yang akan diminum oleh ibu hamil sehingga ibu hamil tersebut memilih untuk tidak mengonsumsinya (Handayani, 2013).

Berdasarkan hasil wawancara, ibu hamil tersebut tidak mengetahui cara mengonsumsi TTD dengan baik dan benar. Rendahnya tingkat pengetahuan pada ibu hamil mengenai TTD terutama pada efek samping minum TTD yaitu mual, nyeri lambung, muntah, sulit BAB atau diare. Sehingga petugas kesehatan perlu menyampaikan bahwa gejala tersebut tidak berbahaya dan tubuh akan menyesuaikan sehingga gejala akan berkurang seiring berjalannya waktu. Selain itu, minimnya pengetahuan mengenai makan makanan yang dapat meningkatkan dan mengganggu penyerapan zat besi. Makanan yang dapat meningkatkan zat besi diantaranya buahbuahan sumber vitamin $\mathrm{C}$ yaitu jeruk, pepaya, jambu biji, serta daging, ikan atau unggas. Sedangkan makanan yang dapat mengganggu penyerapan zat besi diantaranya susu, teh dan kopi, tablet kalsium, dan obat sakit maag. Mitos atau kepercayaan yang salah juga masih terjadi di lingkungan ibu hamil tersebut (Kemenkes RI, 2015a).

\section{4. Indikator Outcome}

Tabel 3. Prevalensi Anemia Ibu Hamil tahun 2017-2019

\begin{tabular}{ccc}
\hline Tahun & Jumlah Prevalensi $(\%)$ & Kategori Masalah \\
\hline 2017 & 66 & Berat \\
\hline 2018 & 54,96 & Berat \\
\hline 2019 & 44,09 & Berat
\end{tabular}

Berdasarkan Tabel 3, diperoleh hasil jumlah prevalensi anemia di Puskesmas Gedongtengen mengalami penurunan selama tiga tahun berturut-turut, yaitu di tahun 2017 sebesar 66\% menjadi 44,09\% di tahun 2019. Meskipun mengalami penurunan, prevalensi di Puskesmas Gedongtengen selama tiga tahun berturut-turut berada di kategori prevalensi anemia berat karena berada di prevalensi $\geq 40 \%$. Batas ambang prevalensi anemia menurut WHO (2011) terdiri dari beberapa kategori, diantaranya kategori masalah berat dengan prevalensi $\geq 40 \%$, kategori masalah sedang dengan prevalensi 20.0-39.9\%, kategori masalah ringan dengan prevalensi ringan dengan prevalensi 5.0-19.9 dan kategori masalah normal dengan prevalensi $\leq 4.9$.

Keseriusan penanganan masalah anemia antara lain didasarkan oleh besarnya prevalensi anemia. Anemia dapat dideteksi salah satunya melalui pemeriksaan $\mathrm{Hb}$. Prevalensi anemia merupakan salah satu indikator keberhasilan program penanggulangan anemia. Apabila anemia pada ibu hamil tidak dapat teratasi, maka perlu adanya evaluasi baik pada ibu hamil maupun pada program. Evaluasi pada ibu hamil misalnya kepatuhan konsumsi TTD, penyakit infeksi kronis/kecacingan, pola makan yang dilakukan oleh ibu hamil, dan mitos yang dipercaya oleh ibu 
hamil. Sedangkan evaluasi pada program misalnya ketersediaan logistik obat, akses masyarakat dan distribusi yang tidak merata, validitas pencatatan, KIE yang diberikan kepada ibu hamil, dan koordinasi dengan lintas program (Kemenkes RI, 2015a).

Optimalisasi distribusi TTD, konseling mengenai gizi seimbang, dan kepatuhan ibu hamil dalam mengonsumsi TTD selama kehamilan hingga nifas perlu dilakukan karena target cakupan pemberian TTD pada ibu hamil belum mencapai target (Dinkes DIY, 2020). Tingkat kepatuhan ibu hamil dalam mengonsumsi tablet Fe berpengaruh terhadap kejadian anemia (Purbadewi et al., 2013). Rendahnya kadar $\mathrm{Hb}$ pada ibu hamil dipengaruhi oleh pola konsumsi ibu hamil, status gizi dan cara mengonsumsi tablet Fe. Dalam rangka meningkatkan konsumsi ibu hamil dapat dilakukan dengan cara menggunakan sumber makanan dari bahan pangan lokal, mencermati status gizi ibu hamil dan mengonsumsi tablet Fe sesuai dengan anjuran dari pemerintah (Fatimah, 2011).

\section{Simpulan}

Berdasarkan hasil kegiatan pengabdian dan pembahasan tentang evaluasi program pemberian tablet tambah darah pada ibu hamil di Puskesmas Gedongtengen, dapat diambil kesimpulan sebagai berikut :

Segi aspek input, tugas tenaga kesehatan yang terlibat dalam program suplementasi $\mathrm{Fe}$ merupakan kolaborasi antara petugas gizi dan farmasi dalam proses pengadaan dan perencanaan TTD untuk memenuhi kebutuhan puskesmas sedangkan bidan bertugas dalam pendistribusian TTD pada ibu hamil. Sumber dana yang digunakan dalam program pemberian TTD pada ibu hamil berasal dari dana APBD, sarana yang digunakan masih belum lengkap yaitu belum adanya petunjuk teknis penatalaksanaan program.

Segi aspek proses, ketersediaan TTD dilaksanakan melalui jalur pemerintah, perencanaan kebutuhan sesuai dengan jumlah sasaran, sosialisasi pemberian telah dilakukan oleh bidan, petugas gizi dan farmasi, penyimpanan TTD sudah sesuai dengan metode FIFO/FEFO dan tata letak gudang sudah sesuai, tetapi kelengkapan dokumen berupa formulir inspeksi gudang dan lingkungan belum tersedia, proses pendistribusian melalui jalur pemerintah yaitu oleh Dinas Kesehatan, cara pemberian TTD dilakukan oleh bidan tidak sesuai dengan pedoman pada ibu hamil anemia, pencatatan dan pelaporan yang dilakukan sudah sesuai pedoman, pemantauan dan evaluasi dilakukan oleh Dinas Kesehatan.

Segi aspek output, cakupan program pemberian TTD belum mencapai target SPM baik untuk Fe1 maupun Fe3 dan tingkat kepatuhan ibu hamil dalam mengkonsumsi TTD dikatakan cukup patuh. Segi aspek outcome, jumlah prevalensi anemia pada ibu hamil selama tiga tahun berturut-turut mengalami penurunan, tetapi selalu berada di dalam kategori anemia berat. Sarannya bagi petugas kesehatan diharapkan memberikan TTD pada ibu hamil anemia sesuai dengan petunjuk di buku pedoman pemberian TTD pada ibu hamil yang berasal dari Kemenkes RI meskipun belum terdapat petunjuk teknis di Puskesmas sehingga prevalensi anemia dapat diturunkan.

\section{Persantunan}

Ucapan terima kasih kepada Universitas Ahmad Dahlan, Puskesmas Gedongtengen dan Dinas Kesehatan Kota Yogyakarta atas izin dan dukungan sehingga kegiatan ini dapat terlaksana dengan baik serta dapat bermanfaat bagi ibu hamil khususnya di Wilayah Kerja Puskesmas Gedongtengen. 


\section{Referensi}

Dewantoro, Nadia, K. P., \& Lailatul, M. (2017). Studi Deskriptif Program Suplementasi Tablet Besi Pada Ibu Hamil Di Puskesmas Kalijudan Kota Surabaya. Amerta Nutrition, 1(4), 308. doi: 10.20473/amnt.v1i4.7144.

Dinkes DIY. (2020). Profil Dinas Kesehatan Kota Yogyakarta Tahun 2019. Yogyakarta: Dinas Kesehatan DIY.

Fatimah, S., Veni, H., Burhanuddin, B., \& Zulkifli, A. (2011). Pola Konsumsi Dan Kadar Hemoglobin Pada Ibu Hamil Di Kabupaten Maros, Sulawesi Selatan. Makara Kesehatan, 15(1), 31-36.

Handayani, L. (2013). Peran Petugas Kesehatan Dan Kepatuhan Ibu Hamil Mengkonsumsi Tablet Besi. Kesmas, 7(2), 83-88. doi: 10.12928/kesmas.v7i2.1042

Haddad, L., Howkes, C., Udomkesmalle, E., Achadi, E,, Bendech, M.A., Ahuja, A., Bhutta, Z., Regil, R.D., Facassi, P., \& Strawn, L.M.G. (2016). From Promise To Impact Ending Malnutrition By 2030. Washington DC: International Food Policy Research Institute

Irianto, K. 2014. Ilmu Kesehatan Masyarakat. Bandung: Alfabet.

Kemenkes RI. (2015a). Pedoman Penatalaksanaan Pemberian Tablet Tambah Darah. Jakarta: Kemenkes RI.

Kemenkes RI. (2015b). Pedoman Program Pemberian Dan Pemantauan Mutu Tablet Tambah Darah Untuk Ibu Hamil Wilayah Program Kesehatan Dan Gizi Berbasis Masyarakat. Jakarta: Kemenkes RI.

Kemenkes RI. (2018). Hasil Utama Riskesdas 2018. Jakarta: Kemenkes RI

Kemenkes RI. (2019). Profil Kesehatan Indonesia 2018. Jakarta: Kemenkes RI

Lacerte., Pradipasen, M., Tamcharoen, P., Imamee, N., \& Vorapongsathorn, T. (2011). Determinants of Adherence to Iron/Folate Supplementation during Pregnancy in Two Provinces in Cambodia. Asia-Pasific Journal of Public Health, 23(2), 315-323.

Miles, M. B., Huberman, A. M., \& Saldana, J. (2014). Qualitative Data Analysis: A Methods Sourcebook: Edition 3. USA: Sage Publications.

Millenium Challenge Account Indonesia. (2015). Pedoman Program Pemberian Dan Pemantauan Mutu Tablet Tambah Darah Untuk Ibu Hamil Di Wilayah Program Kesehatan Dan Gizi Berbasis Masyarakat. Jakarta: Kemenkes RI.

Notoatmodjo, S. (2011). Kesehatan Masyarakat. Jakarta: Rineka Cipta.

Nurmasari, V \& Sumarmi, S. (2019). Hubungan Keteraturan Kunjungan ANC (Antenatal Care) Dan Kepatuhan Konsumsi Tablet Fe Dengan Kejadian Anemia Pada Ibu Hamil Trimester III di Kecamatan Maron Probolinggo. Amerta Nutrition 3(1), 46-51, doi: 10.20473/amnt.v3i1.2019.46-51.

Pavord, S., Bethan, M., Susan, R., Shubha, A., Jane, S., \& Christina, O. (2012). UK Guidelines on the Management of Iron Deficiency in Pregnancy. British Journal of Haematology, 156(5), 588-600. doi: 10.1111/j.1365-2141.2011.09012.x.

Purbadewi, L., Yuliana, N., \& Setiawati, U. (2013). Hubungan Tingkat Pengetahuan Tentang Anemia Dengan Terhadap Terwujudnya Sebuah Perilaku Kesehatan. Jurnal Gizi Universitas Muhammadiyah Semarang, 2(4), 31-39.

Purwati., Didik, T., \& Endang, S. S. (2016). Context, Input, Process, Product Analysis in the Implementation of Iron Supplementation Program in Banyumas, Central Java. Journal of Health Policy and Management, 1(2), 113-20. doi: 10.26911/thejhpm.2016.01.02.06.

Rahmiati, B. (2019). Strategi Perbaikan Program Tablet Tambah Darah Di Kabupaten Tasikmalaya. Midwifery Journal, 4(2), 53-59.

Rooselyn. I. P. T. (2016). Strategi Dalam Penanggulangan Pencegahan Anemia Pada Kehamilan. Jurnal Ilmiah Widya, 3, 1-9.

Septiani, W. (2017). Pelaksanaan Program Pemberian Tablet Zat Besi (Fe) Pada Ibu Hamil. JOMIS (Journal of Midwifery Science). 1(2), 86-92 
Tuju, S, O.,Nugraheni, S, A., \& Wulan, L. R.. (2013). Analisis Implementasi Program Pemberian Tablet Fe ( Besi ) Oleh Bidan Di Puskesmas Wilayah Dinas Kesehatan Kabupaten Minahasa Selatan. Jurnal Manajemen Kesehatan Indonesia, 01(03), 153-58.

Winarno, B. (2012). Kebijakan Publik Teori Dan Proses Edisi Revisi. Yogyakarta : Media pressindo.

World Health Organization. (2011). Haemoglobin Concentrations for the Diagnosis of Anaemia and Assessment of Severity : Geneva $(\mathrm{CH})$

\section{(c) (i) () $\Theta$}

(C) 2022 by the authors. Submitted for possible open access publication under the terms and conditions of the Creative Commons Attribution (CC-BY-NC-ND) license (http://creativecommons.org/licenses/by/4.0/). 